\title{
Prioritizing Warehouse Performance Measures in Contemporary Supply Chains
}

Purpose: Due to the importance of efficiency and responsiveness measures rather than just efficiency measures, this research recognizes both measures when considering overall performance of warehouse operations. Thus, the purpose of this study is to prioritize overall performance measures associated with warehouse operations in manufacturing, third-party logistics (3PL) service provider, and retail industry supply chains.

Design/methodology/approach: The study uses an integrated approach that involves the Qsort method to group measures into four categories. Fuzzy analytical hierarchy process (FAHP) was then used to prioritize individual performance measures within each category and integer liner programming model was used to validate prioritized categories, using the judgement of multiple decision makers across three industries.

Findings: The result shows that the financial category is a dominating performance category in managing warehouse operations across all three industries selected. Within the financial category, cost of insurance accounted for $25 \%$ of total weight of the category, and is considered to be a powerful measure. The financial category is verified by multiple decision makers across three industries, as the most important performance category.

Research Limitations/implications: As part of adopting the proposed methodology in practice, it needs to be guided by overall methodology appropriate for industry-specific contexts.

Originality/value: Key novel aspects of this study are to categorize warehouse operations measures and analyze their perspectives in different industries, understand dominant categories of warehouse operations measures in the contemporary supply chain and finally to explore to what extent current practices lead to achieving efficiency and responsiveness in the selected industries.

\section{Keywords:}

Fuzzy sets, AHP, performance categories, priorities 


\section{Introduction}

In today's business environment characterized by increasing globalization, intense competition and customer sophistication, firms continue to change their global business operations to improve overall performance. In this context, warehouse operations play a significant and critical role in achieving better performance through various improvement methods such as manufacturing postponement and centralized distribution (Nair, 2005; Tse et al., 2012), adopting autonomous vehicle-based storage and retrieval systems (Roy et al., 2012) and optimally coordinating and integrating the interrelated decisions of production sequencing and vehicle routing (Park and Hong, 2009). It is apparent that many smaller warehouses are being replaced by fewer large warehouses to realize economies of scale (de Koster et al., 2007). Furthermore, Bowersox et al. (2013) emphasize the need for integration of global manufacturing with logistics operations including service capabilities and transport support for efficient and effective business performance. The need for integration is exacerbated by increasing competition among businesses, in particular for maintaining required levels of competitive advantage through responsiveness, cost leadership and differentiation (Zailani and Rajagopal, 2005; Cagliano et al., 2006). In addition, businesses are faced with increasing trends of strategic partnerships, outsourcing, virtual logistics and green logistics (de Koster and Warffemius, 2005) for improving overall performance - implying the need for integrating global operations is much more needed than ever before.

In addition to definitions of performance measures, other aspects discussed in literature include key logistics activities, logistics service requirements and the relationships between various factors including the effect of logistics capability on overall performance. Lu and Yang (2010) identify crucial logistics capability dimensions and classify international distribution centre operators. de Koster and Warffemius (2005) distinguish a number of performance aspects associated with warehouse operations, but limited to international operations in Europe, while Cao and Jiang (2013) propose a service capability maturity model for optimum resource configuration solution in public warehouse operations

More recently, Staudt et al. (2015), through a comprehensive literature review of warehouse performance measurement identified a variety of indicators and tools to measure warehouse performance while recognizing the lack of clear definitions for some of those measures. While there is much work on global operations within the context of integration and the impact of overall performance, in particular improving inventory through integration of production sequencing and vehicle routing (Park and Hong, 2009), network design of 
integrated e-supply chains (Dotoli, et al., 2007; Xia and Tang, 2011), and improving global planning through integration of logistics functions (Wang et al., 2012), there is very limited research on performance measures at firm level and relative importance of each performance measure across large supply chains of integrated manufacturing and distribution networks. Furthermore, it has been reported that a performance measurement system consisting of a single measure is inadequate, not inclusive and ignores the interaction among important supply chain characteristics and critical aspects of organizational strategic goals (Beamon, 1999). In addition, Cuthbertson and Piotrowicz (2011), through a common framework for the empirical analysis of performance management systems concludes that performance measurement is a context-dependent process, tailored to specific supply chain requirements. Therefore, it is recommended that for performance measurement systems to be successful, they should include three types of measures - resource measures, output measures and flexibility measures. In the context of measurement and improvement of warehouse performance, most of the research has focused on either warehouse/storage performance at the organization level, limited types of performance measures (e.g. only operational performance) (Sharma and Shah, 2016; Sharma and Shah, 2015) and performance measurement systems for measuring operational performance during disaster response in humanitarian supply chains (Santarelli et al., 2015). There has been limited research on the impact of warehouse performance on overall performance in global supply chains, which are increasingly characterized by supply chain disruptions (Samaranayake et al., 2011; Lee and Rha, 2016), increasing competitiveness with customers demanding quick response and speedy deliveries (Nair, 2005). This study aims to address these issues. Consequently, the key research questions are twofold: (i) What are the key warehouse performance measures and categories? (ii) What are the priorities of those categories from a contemporary supply chain perspective? Thus, the purpose of this study is to categorize warehouse operations measures and analyze their perspectives in different industries, understand dominant categories of warehouse operations measures in the contemporary supply chain and finally to explore to what extent current practices lead to achieving efficiency and responsiveness measures in the selected industry context. Consequently, this research examines how overall performance measures are influenced by individual performance measures by analyzing the relative importance of each one within each category and verifying ranking/priorities of categories through judgement of multiple decision makers from three industries (manufacturing, 3PL and retail) selected. Overall performance is considered by incorporating a combination of efficiency and responsiveness related performance measures associated with warehouse operations. The research is based on the 
comparison of three types of organizations operating in Asia - manufacturers, retailers and third party logistics companies (3PLs). It is important to study all three types as they all operate warehouses distinctly even though they may work in the same supply chain and thus, their operational perspectives and motivations may be different. The research adapts a three-stage methodology that uses Q-sort method to categorize warehouse performance measures, fuzzybased analytical hierarchy process (AHP) approach to prioritize measures within each group, and validate prioritized (ranked) categories, using judgement of multiple decision makers across three industries. The proposed three-stage approach is an extension of commonly adopted hybrid approach of Q-sort method and AHP for prioritizing performance measures. It incorporates three types of measures (resource, output and flexibility) and validates ranking/priorities of categories using judgements from multiple decision makers. This study provides important theoretical contributions to the literature on broader warehouse management and, in particular, selecting the right combination of performance measures from a range of efficiency and responsive related measures for not only improving global operations at firm level, but also making right choices of performance measures as required by the competitive pressures of the supply chain that warehouse operations are engaged in. Using practice-based view (Bromiley and Rau, 2014), this study suggests what current practices companies need to reconfigure to achieve both efficiency and responsive measures in the warehouse operations context. Within the context of warehouse management, this study contributes to an understanding of the measurement of warehouse performance. According to Faber et al. (2013), warehouses have become an increasingly complex context to manage and this study, therefore, investigates performance measures within an increasingly complex environment. The remainder of the paper is structured as follows. Literature review on broader warehouse management and specific performance measures are presented next, followed by the research methodology and data analysis. The research findings section is followed by discussion and conclusion which include research implications for industrial practitioners as well as limitations and future work.

\section{Literature Review}

Improving warehouse performance in global operations is a demanding task, particularly within an environment of increasing competition, customer sophistication and uncertainty in demand and supply in large supply chain networks. This is evident from recent trends in 
increasing demand for value-added services, automated processing and information technology (IT) (Min, 2006). In addressing competitive pressures of business, Nair (2005) claim that firms are adopting policies such as manufacturing postponement and centralized distribution to improve their operational performance. By using a conceptual model of operational policies and performance, the study of Nair (2005) shows that there is a positive relationship between operational policies and performance.

\subsection{Performance measures and evaluation}

The measurement of performance was highlighted by Chia et al. (2009) as an important activity within the context of supply chains as it helps to drive strategic performance. This may be because metrics can help to understand the outcomes of organizational activity (Jothimani and Sarmah, 2014). Warehouses not only play an important connecting role in the supply chain, they also impact cost and have become complex entities to manage. It is important, therefore, to continuously investigate how their performance is measured (Faber et al., 2013). Various studies have identified a number of performance aspects in different contexts of warehouse management, including: productivity, flexibility and outbound logistics (de Koster and Warffemius, 2005), productivity, delivery competence and responsiveness (Nair, 2005), service capability through storage, transportation, cost control and time control (Cao and Jiang, 2013), economic and technical related performance measures (Johnson and McGinnis 2011), inventory accuracy, timely delivery service, individual order fulfilment, flexible value-added service and responsiveness to special customer requests (Min, 2006), three critical logistics service capabilities (Lu and Yang, 2010), and cost, throughput, space utilization and service (Gu et al., 2010).

Performance evaluation has been considered from various perspectives including warehouse design and operation (Gu et al., 2010), improvements of warehouse operations, in particular, postponement operations (Tse et al., 2012) and relationships between operational policies and performance (Nair, 2005). Beamon (1996) presented characteristics which make a performance measurement system effective and they are inclusiveness, universality, measurability and consistency.

There are many performance measures identified by various studies. Lu and Yang (2010) indicated two different types of performance measures: financial and non-financial measures. Apart from broader performance measures such as those mentioned above, Lu and Yang (2010), based on a comprehensive literature review, identified seven common measures 
which are profit rate, sales growth rate, reduced operation cost, return on investment, market share growth, customer relationship and customer satisfaction.

Given the large number of performance measures associated with warehouse operations, improvements have been sought in various contexts including the need for developing logistics capabilities (Lai, 2004), direct linkage between quality customer service and supplier's performance (Sharma et al., 2004) and the impact of the complexity of a warehouse on the warehouse's performance (Faber et al., 2002).

\subsection{Improvement practices and performance}

Since the inception of various concepts on logistics systems and distribution practices, many theoretical and empirical studies have reported outcomes of various practices to achieve superior performance with lower investment (Chen et al., 2007). Improvements in warehouse performance are achieved in many ways including practices that enhance operations efficiency and flexibility using autonomous vehicle-based storage and retrieval systems (Roy et al., 2012), and adopting manufacturing postponement and centralized distribution techniques with value chain flexibility (Nair, 2005). In addition, Min (2006) proposed a warehouse management system that is designed to speed up order turnaround time, improve inventory accuracy, provide instant order status information, manage warehouse space and enhance labour productivity. Similarly, Tse et al. (2012) proposed a hybrid intelligent system for improving postponement operation in warehouses, by integrating Case-Based Reasoning and Fuzzy Logic.

Many practices or systems proposed so far concentrated on cost reduction, time reduction and reliability aspects of performance measures, such as delivery of products in a cost effective manner through manufacturing postponement and centralized distribution (Pagh and Cooper, 1998) and meeting expected demand with the lowest possible cost with interfacility mold transfers (Aghessaf 2007). Others include lower operational cost and improved mass customization flexibility through postponement operation in warehouse (Tse et al., 2012), inventory accuracy, timely delivery service and individual order fulfilment through warehouse management system (Min, 2006), service capability and optimization of warehouse configuration through warehouse product service system (Cao and Jiang, 2013) and meeting delivery deadlines with reduced inventory using trans-shipments (Lau and Nakandala, 2012). Studies have also reported on technical efficiency aspects of warehouse operations (Johnson and McGinnis, 2011), performance at firm level, distribution centers (Lu and Yang, 2010; Roy et al., 2012), warehouse design and performance evaluation (Gu et al., 2010) 
The literature presented shows that there has been much academic interest in the performance of warehouses and the use of performance measures. However, it has also been shown that supply chains and warehousing operations have become more complex. While there is significant research on understanding practices to improve certain measures, it is not well known how to categorize performance measures and to target key performance measures at warehouse level within specific industries. Warehousing operations are now carried out by different types of organisations in the supply chain including manufacturers, suppliers and 3PL organisations. There is yet no direct ranking or comparison of warehousing performance measurement across these types of organisations and particularly from a quantitative perspective. This is a significant gap bearing in mind that the different positions that these types of organisations occupy in the supply chain may affect their priorities when it comes to managing warehousing operations. In particular, a better understanding of the differences in weighting and prioritization given to warehousing performance measures could provide insights into how to improve warehousing operations from a balanced resilience and an integrated supply chain perspective. This study, based on the practices and experiences of organisations in four South East Asian countries (Thailand, Vietnam, Malaysia and Indonesia) addresses this gap. This is achieved through a mixed research design approach with both model development and experimental investigation. The proposed hybrid approach categorizes performance measures and captures the main performance measures associated with global warehouse operations and relative importance based on prior knowledge using situational analysis of fuzzy logic as part of a broader approach. Relative importance of key performance measures is based on fuzzy AHP and are compared with weights obtained from fuzzy-based group prioritization approach using fuzzy pairwise comparison matrices.

\section{Research Methodology and Data Analysis}

The proposed research methodology comprises of three stages. The main focus of the first stage was to determine the potential performance measures applicable in managing warehouse operations. This stage involved, content validity analysis using (i) identification of performance measures from a comprehensive literature review on broader supply chain performance and categorizing those measures using Q-sort method (Rajesh et al. 2011) through interviews of practitioners involved in managing warehouse operations. The second stage involved prioritization of performance measures within categories using fuzzy AHP method. At the third stage, priorities/ranking of performance categories are validated using judgements 
of multiple decision makers. The three-stage research methodology outlined above is summarized and is presented in a schematic view as shown in Figure 1.

Stage 1: Determining the potential performance measures in managing warehouse operations Content validity analysis

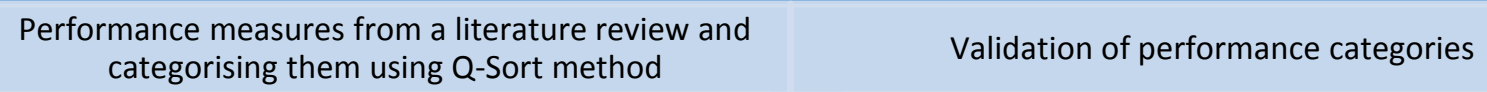

Stage 2: Establishment of relative weight of each performance measure

Fuzzy sets for each performance measure
Analytical hierarchical process (AHP) for prioritizing each performance measure

Stage 3: Validation of priorities/ranks of performance categories using judgements of multiple decision makers from three industries (manufacturing, 3PL and retail)

Relative weights of each performance measure under four categories (Accuracy, Resource utilisation, Financial outcome, and Responsiveness and Flexibility

Figure 1: Three-stage research methodology

\subsection{Categorization of performance measures}

The literature review on performance measures focusing on warehouse operations identified thirty-two performance measures as presented in Table 1.

\section{Insert Table 1}

Nineteen warehouse managers from organizations in South East Asia (Thailand, Vietnam, Malaysia and Indonesia) were interviewed and asked them to classify each performance measure into one of four different categories. This activity was carried out during a Corporate Annual Meeting held in Bangkok, Thailand where the senior management staff representing regional offices and the three selected industries attended. The four categories were selected based on the level 1 performance metrics of supply chain operations reference 
model which include accuracy (Reliability); flexibility and responsiveness; cost; assets (Resources) (Huan et al., 2004). In this context, accuracy can be measured using metrics associated with inventory and warehousing functions of supply chains (Hou et al., 2010) and is directly influenced by the level of integration of those functions supported by computer integrated manufacturing.

Subsequent analysis of the interview findings indicated that out of thirty-two performance measures, nineteen performance measures could be classified into four categories with an acceptable level of Cohen Kappa Coefficient (Cohen, 1960). Hence, Table 2 and Figure 2 show the Cohen Kappa of 3 industries. These are: (i) Accuracy ( $\kappa=0.8175)$, (ii) Resources Utilization $(\kappa=0.7317)$, (iii) Financial Outcomes $(\kappa=0.7504)$, and (iv) Responsiveness and Flexibility $(\kappa=0.7576)$ while Table 3 shows Cohen Kappa of manufacturing, retail, and 3PL industries.

\section{Insert Table 2 \\ Insert Table 3}

In the second stage, the study applied an integrated Chang's (Chang, 1996) extent analysis on fuzzy AHP to determine the relative weight of importance among performance measures and the four categories identified above. Relative weights of importance of performance measures, based on fuzzy AHP are compared with those of fuzzy group prioritization method. Chang's extent analysis method is recognized as unsuitable when there are cases of having irrational "zero weight" of criteria which cause wrong priority weights (Wang et al., 2008). Therefore, Chang's extent analysis method on fuzzy AHP is a reliable method except in such cases (Vaziri and Beheshtinia, 2016). Since this study did not encounter the problem of a zero-weight for any criterion, Chang's extent analysis was deemed suitable. Details are presented in the subsequent section.

\subsection{Prioritization of performance measures using Fuzzy AHP}

After validating the constructs of performance measures in managing warehouse operations through Q-Sort method, analytical hierarchy structure was established to determine the relative weight of importance among constructs (categories) and measures. In this study, a panel of experts was selected based on their experience. Nahm et al. (2002) argue that the number of experts should be large enough to assure multiple perspectives, and small enough to 
make the research manageable. The experts came from three different industries: manufacturing, retail, and $3^{\text {rd }}$ Party Logistics Provider (3PL) with operations in South East Asia (Thailand, Vietnam, Malaysia and Indonesia). As shown in Table 4, twenty practitioners were interviewed during June-August 2012.

Insert Table 4

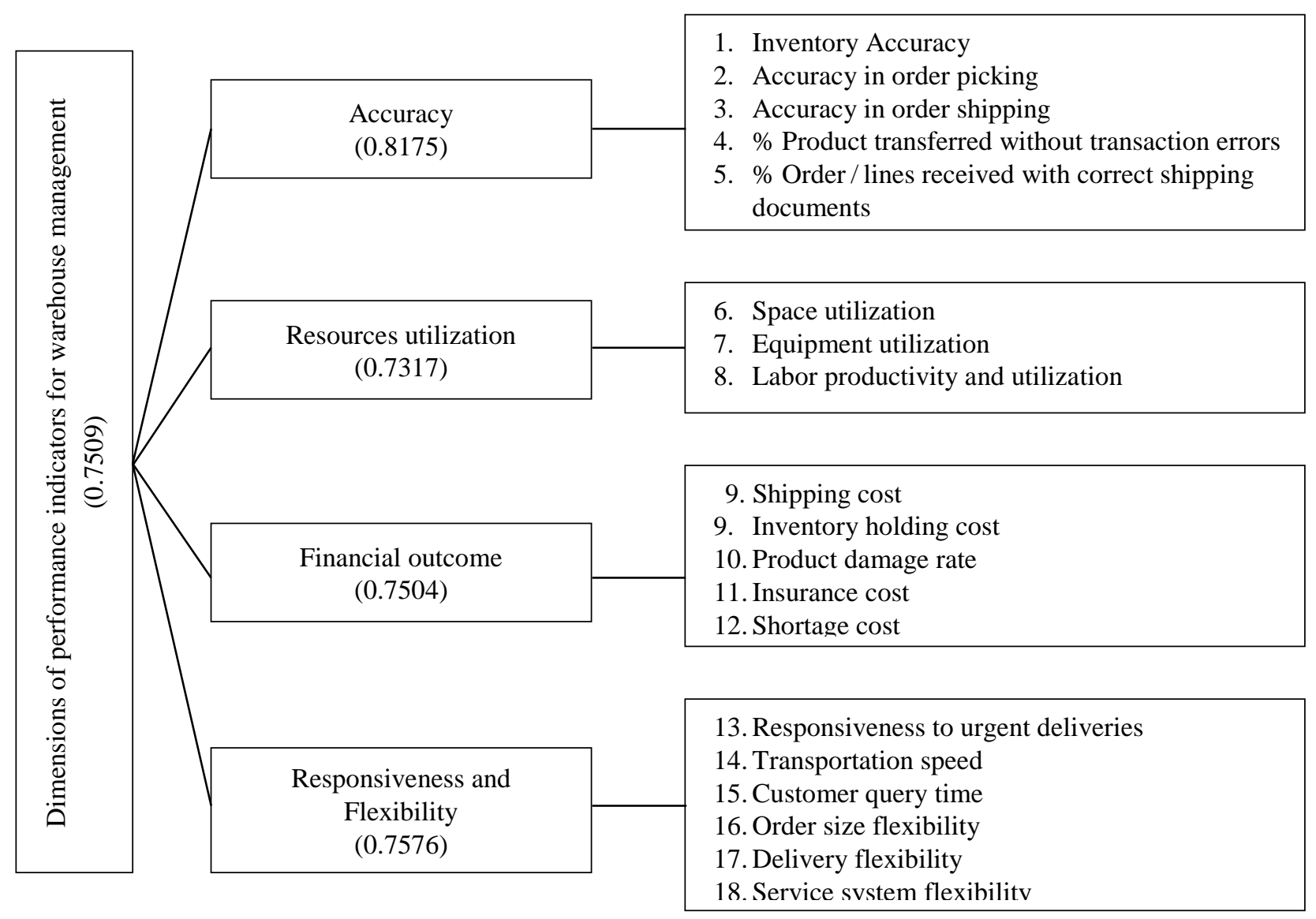

Figure 2: Overall result from Q-Sort method

In order to determine the judgment matrix, these experts were asked to pairwise comparable categories using linguistic terms which were subsequently expressed by fuzzy numbers. Many published studies on prioritizing performance measures have developed a wide variety of models related to experts' judgments (Reisinger et al., 2003; Roberts and Philp, 1996; Chan and $\mathrm{Wu}, 1998$ ). Among many multiple criteria decision making (MCDM) methods, Analytic Hierarchy Process (AHP) has been widely used by many researchers (Wang et al., 2008) since AHP provides an ideal tool for a sequence of multi-objective decision making problem (Dong, 2013). Although the traditional AHP method is suited to prioritizing performance measures in order to incorporate the opinion of experts (stakeholders or decision- 
makers), however, it cannot reflect human thinking because of the imprecision and vagueness of decision makers' judgments. AHP with its fuzzy extension, so-called fuzzy AHP, therefore was developed to compensate the deficiency in traditional AHP and it has been widely used in the past by many studies for prioritization (Ayağ, 2005; Chen et al., 2006). In this study, fuzzy AHP was applied to obtain more decisive judgments by weighting the performance measures in the presence of vagueness of experts' preferences. The approach of fuzzy AHP to calculate weights of performance measures is described as follows:

(i) Develop a hierarchical structure for prioritizing the performance measures:

A fuzzy AHP model (Figure 3), based on the identified potential measures and associated categories is developed and presented. With a hierarchical structure, a complicated and complex problem is converted to a hierarchical system of elements. The hierarchical structure systematically accommodates the use of expert judgment.

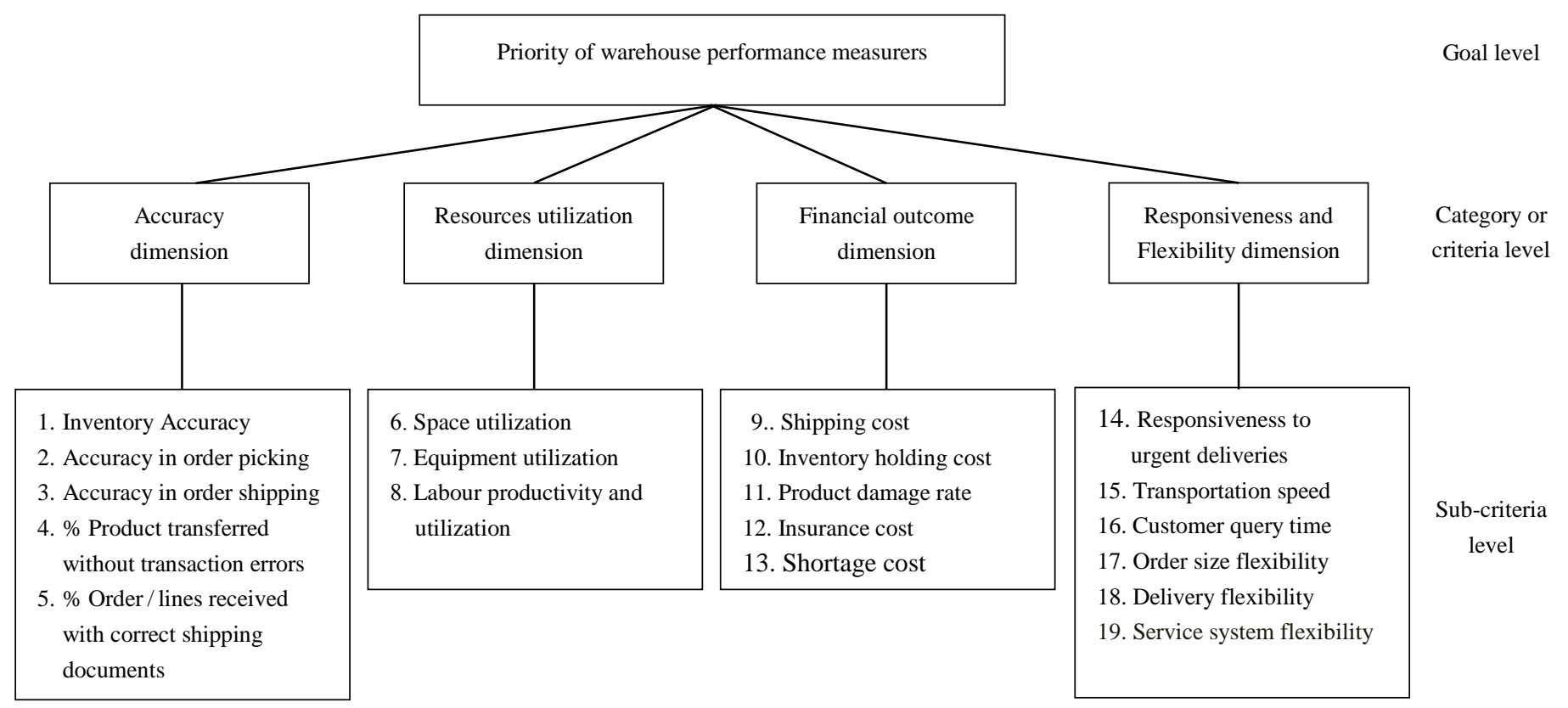

Figure 3: Hierarchy structure of warehouse performance measures 
(ii) Establish a fuzzy judgment matrix (or a pairwise comparison matrix):

A panel of experts was asked to make pairwise comparisons for elements and questionnaires were provided to collect information from the experts. Each expert was asked to assign linguistic terms based on his/her subjective judgment, to the pairwise comparisons by asking which one of two categories is more important and how much more important it is with respect to the preceding element. In this case, linguistic terms adopted include five different scales: Equally important (EI), Moderately important (MI), Fairly important (FI) Very important (VI) and Absolutely important (AI). In decision-making, each expert gave his/her preference on the categories identified in the above step (Step 1) of the procedure. In the case of pairwise comparison of categories using linguistic terms, each expert's judgment resulted in (n-1) of comparisons for $n$ number of categories. For the four categories identified above, there are six pairwise comparisons from each expert. The fuzzy judgment matrix reflects the relative importance of the decision categories. After recoding answers from the experts in linguistic terms, these linguistic judgments are then converted to triangular fuzzy sets.

(iii) Combine the opinions from several experts by using geometric mean:

The perception of each expert varies according to individual experience and knowledge. In order to get a consistent and fair outcome from several experts' subjective judgments, the informed judgments were aggregated through the geometric mean of individual experts' judgments. By using the geometric mean method to derive the fuzzy weight, therefore, different judgmental values can be converted to one element in the fuzzy judgment matrix. Let $M_{i j}^{k}$ represent a subjective judgment of the $k^{\text {th }}$ expert for the relative importance of two elements (the $i^{\text {th }}$ element and the $j^{\text {th }}$ element), then the fuzzy geometric mean $M_{i j}$ from $m$ experts is shown in following equation.

Fuzzy geometric mean, $M_{i j}=\left(M_{i j}^{1} \otimes M_{i j}^{2} \otimes \cdots \otimes M_{i j}^{m}\right)^{1 / m}$

(iv) Repeat the calculation of the local priority weights for other categories of performance measures:

(v) Calculate the global priority weight of each element:

The global priority weight of each element is calculated by multiplying its local weight with its corresponding weight along the hierarchy. Tables 5-9 show the results from Fuzzy AHP process from the three different groups of experts while Table 12 presents the overall 
result. There are a variety of extensions to the Fuzzy AHP approach that can increase its usefulness for managerial decision making. For prioritizing the performance measures, in this study, they were grouped into categories. These categories are compared pairwise first, then the performance measures are compared pairwise with respect to their criteria. The performance measures were not compared to their counterparts across the categories. In doing so, a smaller number of the pairwise comparisons are required.

Table 5 shows that financial outcome is the most important measure across all three industry sectors. Retailers however, place significantly less emphasis on resources utilization compared to the other two sectors. Rather, they prefer to emphasize responsiveness and flexibility

\section{Insert Table 5 \\ Insert Table 6}

With respect to the accuracy dimension, the percentage of products transferred without transaction errors and the percentage of orders received with the correct shipping documents were deemed to be most important. Conversely, Accuracy in order picking was deemed least important across the three industry sectors.

\section{Insert Table 7}

Within the Resource Utilization category, Equipment utilization was the most important measure across all industry sectors while Space Utilization was the least important.

\section{Insert Table 8}

Within the Financial outcomes category, cost of insurance was seen as most important. However, it is not clear whether this is an indication that the costs are too high or if it is an acknowledgement that insurance is seen as a priority to minimize financial loss. The least important measure was inventory holding cost. This may be because of the adoption of inventory practices such as JIT that minimize inventory holding.

\section{Insert Table 9}


With respect to responsiveness and flexibility, flexibility of order size was seen as most important across all three industry sectors and particularly by the logistics service providers. This may be because different order sizes affect their loading factors and efficient use of delivery vehicles. In contrast, the logistics services providers place virtually no importance on customer query time.

\section{Insert Table 10}

(vi) Validate the priorities/ranks of performance categories using judgements of multiple decision makers

Priorities of performance categories identfied by weights from AHP (Table 10) are validated by minimisation of deviation between the ranking of each category by individual decision maker and weighted average of each category. Decision makers are selected from the group of 20 warehouse managers that particpated in the study (Table 4). The following key variables and paramters were defined for the minimisation of deviation using integer programming model.

$\mathrm{DM}_{\mathrm{j}}=\mathrm{j}^{\text {th }}$ decision maker $(\mathrm{j}=1,2, \ldots . . \mathrm{m})$

$\mathrm{r}_{\mathrm{ij}}=$ Rank of the ith performance category $(\mathrm{i}=1,2, . . \mathrm{n})$ by $\mathrm{jth}$ decision maker $(\mathrm{j}=1,2, \ldots \mathrm{m})$

$\mathrm{y}_{\mathrm{j}}=$ Weightage assigned to $\mathrm{jth}$ decision maker, depending on the importance of decision maker for the evaluation of ranking of categories

$Y_{i}=$ Weighted average of performance category $i$

Each decision maker is assigned with a weight (less than 1, making total weight of all decision makers to 1). Since ranking/priorities are considered from 1 (the most prominant) to $\mathrm{n}$ (least prominent), the reciprocal of weight of each decision maker is considered for arriving at weighted average for each category (Yi). Thus, Yi is comuted as follows:

$$
Y_{i}=\sum_{j=1}^{m}\left(r_{i j} * 1 / y_{j}\right) \quad i=1 \ldots \ldots n
$$

In this case, there are four categories ( $\mathrm{i}=1$ to 4$)$ and six decision makers (DM1-DM6), (three from manufacturing, two from 3PLs and one from retail) for the validation of priorities/ranks. In this case, only six decision makers are selected to represent all three entities 
of the selected supply chain (Manufacturer, 3PL and Retailer) and they were senior managers at respective organisations. For this stage, it was necessary to involve only senior executives and not all stakeholders. This is because senior managers have organizational responsibility for setting priorities regarding choice and prioritization of organizational measures. Therefore, their roles and responsibilities in the organization are different from the experts used in the first two stages of the research.

Since reciprocal weighted average of each performance category is considered, minimum deviation between weighted average and individual ranks is achived by maximizing the reciprocal deviation, represented by Z. Further, it is emphasied using multiplication of reciprocal deviation (sum of $\left|\mathrm{r}_{\mathrm{ij}}-\mathrm{Y}_{\mathrm{i}}\right|$ ) and rank (Decision variable - $\mathrm{X}_{\mathrm{i}}$ ) for each performance category (i). For example, when reciprocal deviation is largest, it will be multiplied by the largest rank (least priority). Thus, the problem formulation is given by:

Objective function

$$
\operatorname{Max} Z=\sum_{i=1}^{n} \sum_{j=1}^{m}\left|\left(r_{i j-} Y_{i}\right)\right| X_{i}
$$

Subjected to,

$$
\begin{aligned}
& 1 \leq X i \leq n \quad \forall i(1,2, \ldots \ldots, n) \\
& X i \neq X k \quad \forall i, k \text { such that } i \neq k \\
& X i \text { is integer } \forall i(1,2, \ldots \ldots, n)
\end{aligned}
$$

Equation (1): Weighted average performance of category i

Equation (2): The objective function of the model which maximizes deviation between the weighted average and individual rankings from different decision makers.

Equation (3): Restricts the ranking of $\mathrm{n}$ performance categories from 1 to $\mathrm{n}$ only.

Equation (4): Ensures that no two performance categories are given the same rank by the same decision maker

Equation (5): Integer value of the rank is ensured.

The individual ranks by each decsion maker for each performance category and evaluated weighted average are given in Table 11.

Insert Table 11 
The proposed interger linear programming (ILP) model using individual ranks $\left(\mathrm{r}_{\mathrm{ij}}\right.$ ) by decision makers $\left(\mathrm{DM}_{\mathrm{j}}\right)$ and evaluted weighted average $\left(\mathrm{Y}_{\mathrm{i}}\right)$ values (Table 13) was solved using Excel Solver. The solution ( $X_{i}$ values) of ILP model are given by: $X_{1}=3, X_{2}=2, X_{3}=1$ and $\mathrm{X}_{4}=4$. In this case, the performance category of finacial outcomes is identified as the highest priority $\left(\mathrm{X}_{3}=1\right)$ while the performance category of responsiveness and flexibility is the least priority $\left(\mathrm{X}_{4}=4\right)$. Thus, the performance category of finacial outcomes is validated by judgements of multiple decision makers as the prominent ranking/priority of warehouse performance measures in contemporary supply chains.

\section{Research Findings}

This section discusses the findings of our study from several perspectives. First the study highlights the dominant performance measures in four dimensions using the literature review. Secondly the study summarizes the reflections of practitioners about grouping performance measures under various dimensions. Finally, the study presents the findings of prioritization with respect to dominant dimensions and influencing performance measures.

\subsection{Dominant performance measures based on literature review}

Previous studies, irrespective of industry emphasized on performance measures related to three aspects - accuracy, resource utilization and financial. The dominant measures cited by researchers in the three categories are as follows (Huan et al., 2004; Shepherd and Günter, 2006; Akyuz and Erkan, 2010)

a) resource utilization measures are capacity utilization and labor productivity and labor utilization;

b) accuracy measures are on-time delivery, order cycle time, inventory accuracy and stock turnover

c) financial measure is shipping cost

Interestingly there were not many studies that gave due importance to responsiveness and flexibility measures except transportation speed. 


\subsection{Reflections of practitioners}

Practitioners opined similar views with respect to previous studies, irrespective of industry and were more consistent in grouping performance measures related to accuracy, resources utilization and financial outcome categories than flexibility and responsiveness. Out of the three aspects their perception about accuracy is almost consistent. In order to make these reflections applicable to specific industries, future studies may consider expanding the approach adopted in this study across other industries. This study is based on inputs from two distinct industries: Electronics/Electrical (High tech) and Automotive Parts/Components manufacturing. These two industries have similar warehouse operations environment in nature such as working under the lean, supply chain, and total quality management.

\subsection{Prioritization of performance categories and measures}

Composite rating based on three industries suggest that warehouses focus more on efficiency related measures. Out of four categories, financial outcome had prominence in all industries selected for the study (Table 12). Warehouse operations until now focus on how to minimize cost by excluding non-value added activities. Resource utilization and accuracy construct trails after financial outcome category because all the industries attempt to effectively utilize their resources without any loss. Responsiveness and flexibility category did not have prominence in the overall analysis. The focus on cost rather than responsiveness finds resonance with the findings by de Koster and Balk (2008) that Asian warehouses pay more attention to cost, resource utilization and accuracy measures. The influencing individual performance measures within each category are discussed below.

Cost of insurance, shortage cost and shipping cost are considered to be the dominant measures in understanding the financial dimension in warehousing operations. It is interesting to note that cost of insurance is considered as the most important measure rather than shipping and shortage costs. Equipment utilization and labor utilization have been considered as dominant measures to capture resource utilization dimensions. Industrial practitioners place more value on equipment and labor compared to space utilization.

Two measures - percentage product transferred without transaction errors and percentage orders/lines received with correct shipping documents were rated as the most valued measures to capture accuracy compared to other accuracy measures related to inventory, order picking and shipping. Out of six measures considered for the study order size flexibility is the most important followed by responsiveness to urgent deliveries. Interestingly transportation speed mentioned by various researchers was considered as the least influencing performance 
measure by the practitioners. In the future, practitioners need to evolve practices to concentrate on transportation speed and responsiveness related measures.

\subsection{Industry-related findings}

The prioritization of the four categories and their performance measures are discussed below with respect to industries considered in this study. Practitioners representing the manufacturing industry considered financial outcome category and resource utilization dimension as the paramount performance measures of warehousing. In terms of measures within each category most of the results are synonymous with overall results. Few deviations with respect to overall analysis are as follows: In the accuracy category, manufacturers gave more importance to inventory accuracy than percentage product transfer without transaction errors. In the responsiveness and flexibility category, manufacturers prefer to consider flexibility of service systems to meet as an important measure than responsiveness to urgent deliveries. This study also found that representatives from third party logistics service providers gave similar weight to categories as the manufacturers did. They gave importance towards financial outcome category and resource utilization category. As suggested by de Koster and Balk (2008), Asian warehouses being primarily privately owned are more focused on cost compared to their European counterparts which focus more on responsive measures and practices. There are few variations in the prioritization of measures within each dimension per industry when compared to the overall analysis. The deviations within each category are as follows. Accuracy in order picking was given more importance than percentage orders/lines received with correct shipping documents. Shipping cost in financial category is considered to be more important than cost of insurance. Response to urgent deliveries was considered to be more important than order size flexibility in the responsiveness and flexibility category. Finally, this study shows that the financial outcome and responsiveness and flexibility categories are the most performance categories in the retail industry. It is interesting to note that retail industry is the only one which gives due importance to the responsiveness and flexibility category. The top two measures within all categories indicated by the three industries are similar to the overall analysis except the responsiveness and flexibility category. Customer query time was more prominent than order size flexibility. 


\section{Discussions and Conclusions}

This study set out to achieve three key aims; firstly, to identify and categorize performance measures; secondly, to investigate and establish relative importance of individual performance measures within the context of performance categories; and thirdly, to validate priorities of performance measure categories using judgement of multiple decision makers selected from three industries. Using integrated research methodology, the study was able to categorize 19 performance measures into 4 categories based on Q-sort analysis. Perhaps the key issue is not the measures that were chosen but the measures that were not chosen by the experts. For example, if considering the 'financial outcome' category, a number of seemingly important measures such as inventory obsolescence, maintenance cost, number of stock-outs and stock turnover were not selected. Clearly, all warehouse operations would incur a maintenance cost and would be subject to a stock turnover. In addition, depending on the organization and industry involved, obsolescence and stock-outs could be an issue. The exclusion of these measures could imply one of a number of things. Firstly, it could imply that the costs associated with these measures are not large enough for the measures to be seen as important by the experts. Secondly, it may be because the importance of these costs could vary from industry to industry and therefore, the collective perception of importance is not as high as the factors that were chosen. Thirdly, it may be that some of the costs are 'hidden', not immediately obvious or are not perceived as attributable to warehouse costs. For example, stock turnover and obsolescence may have significant financial implications but can be argued to be 'hidden' costs. However, the fact that they are also not associated with other performance categories (e.g. obsolescence and stock turnover may also affect resource utilization) raises an interesting question about the perception of performance measures and corresponding practices in the industry. Most of the measures that were not chosen are bottom line measures which may not influence process performance (Ganesan et al., 2009). The key suggestion here is that there is no clarity about why some performance measures are associated with certain performance dimensions and others are not. There may be several influencing factors such individual company systems, industrial sector practices or even national cultures.

With respect to the results from fuzzy logic analysis, it is interesting that the manufacturers place the greatest emphasis on financial outcomes and resources utilization while focusing little on accuracy and responsiveness/flexibility. Conversely, their customers, the retailers place as much emphasis on responsiveness/flexibility as they do on financial outcomes while also rating accuracy as important. On the contrary, they rate resource 
utilization quite low. The suggestion from these findings are that in spite of the much avowed understanding of customer needs and striving to fulfill them, manufacturers continue to manage for cost by following lean practices thereby shunning flexibility. This observation suggests in future manufacturing industry should focus on lean practices to achieve both performance measures. On the other hand, retailers maintain a focus on cost by demanding flexibility and accuracy. This diametric opposition raises questions about whether the methodological and technological advances that have been developed to bridge these gaps (e.g. VMI, EDI, forecasting) have had any fundamental influence on practices in both the retail and manufacturing sectors. These challenges may be, in part, due to relatively less developed acceptance of these advanced technological solutions in developing parts of Asia when compared to developed western countries. It may also suggest that manufacturers, retailers and 3PLs in this part of the world are still largely focused on their own organizations rather than overall supply chain efficiency and integration.

\subsection{Individual performance measures}

Analysis of individual performance measures within the context of the three sectors provides interesting insights. With respect to 'Accuracy', there appears to be a good spread of emphasis across all five measures. However, with respect to 'Resource utilization' both the retailers and manufacturers focus primarily on equipment utilization and noticeably less significantly on space utilization. In contrast, the third-party logistics companies have a more even spread across the three measures. In particular low emphasis of the retailers may be the result of the following two factors. The first, as discussed in the previous paragraph, is their requirement for flexibility which implies less stock-holding and consequently, a reduced focus on space utilization. The second is the fast moving nature of the retail industry and the consequent ability to hold fewer inventories in warehouses. Indeed many large retailers mainly make use of distribution centres which hold inventory only for very little time before sending them out to different retail locations. It may well be that the core need to efficiently cross-dock products from manufacturers and third-party logistics organizations is a key reason why retailers focus particularly on equipment utilization. On the other hand, manufacturers and, in

particular, retailers who are tasked with the flexibility requirements of the retailers would have the practice of holding more inventory and so they are more focused on space utilization.

The 'Financial outcomes' category suggests that compared to retailers, manufacturers and 3PLs are more focused on product damage rate and less on inventory holding cost. The focus on product damage rate is understandable since products carry a higher risk of damage 
during transportation. Finally, with respect to 'Responsiveness and Flexibility', retailers and 3PLs place more emphasis on transportation speed. This could reflect their closeness to the consumer and variability in demand. It is evident from our study that retailers and 3PLs are more concerned about significant performance measures than bottom line measures. However, it could also be due to the need to deliver products within allocated time slots. In addition, manufacturers and 3PLs place more emphasis on responsiveness to urgent deliveries and order flexibility. This reflects the requirements of the retailer and may be related with the desire of retailers to hold minimal inventory. From a theoretical framework perspective, performance categories associated with warehouse operations in the supply chain are closely related to supply chain resilience framework (Pettit et al., 2010) where performance categories such as capability dimensions contribute to balanced resilience and improved performance. For example, responsiveness and flexibility category identified as a prominent measure of 3PLs and retailers is identified as one of the capabilities of supply chain resilience, contributing to balanced resilience involving multiple tiers of suppliers and customers of contemporary supply chain (Pettit et al., 2010).

\subsection{Research implications, limitations and further work}

The findings from this study have important implications for industry. For industry, there is a need to understand performance measures and also identify and use performance measures that not only complement their operations but that also reflect the priorities of their supply chain partners. Manufacturers and 3PLs need to understand that retailers are particularly keen on responsiveness and flexibility and so they need to focus more on this too. The disconnection between the priorities of Asian retailers, 3PLs and manufacturers suggests that there is a need for a balanced approach to managing warehouse operations from the supply chain partners. In particular, 3PLs and manufacturers need to change the focus of their warehousing operations and management. They need to enable their processes to be more responsive and flexible in order to react quickly to changes in the market. In an environment where consumers are demanding fast response from both online and traditional retailers, the manufacturers and 3PLs that service these retailers will have to rebalance their strategies and improve their operational efficiency, responsiveness and flexibility as well as the accuracy of their operations. This may imply that they need to co-ordinate their warehousing operations more closely with those of the retailers particularly as retailers are focused significantly on reducing inventory holding costs. 
There are particular implications for 3PLs which find themselves as the intermediaries between manufacturers and retailers. They need to carefully balance the conflicts between their upstream and downstream supply chain partners. For example, manufacturers are more focused on space utilization than retailers while there are also noticeable differences in focus on inventory holding costs and inventory accuracy. Therefore, 3PLs need to play a pivotal role in smoothing out supply chain imbalances particularly with respect to inventory management. This may imply that they sometimes act as temporary buffers between manufacturers seeking efficiency and retailers seeking agility. The implication is that much of the smoothing of the supply chain will be the responsibility of 3PLs. It is therefore important that they pay particular attention to the cost implications of playing this role and ensure that taking on the extra risk and responsibilities do not adversely affect their business. This does not appear to be a role that Asian 3PLs have embraced so far.

For retailers, they need to appreciate the challenges that manufacturers and 3PLs face with respect to responsiveness and particularly as it affects the cost of warehouse operations. While the need for responsiveness is important for retailers to satisfy ever-demanding consumers, there is a cost associated with this, in which retailers may not wish to bear. It is important for retailers to understand that manufacturers and 3PLs cannot indefinitely bear the cost of increasing demands for flexibility and responsiveness. To address these challenges, they need to share more relevant information with the supply chain partners and where possible, seek closer integration by adopting Vendor Management Inventory (VMI) for example.

With respect to study limitations, in this research, performance measures were considered across efficiency and responsive categories, but the responsive category is limited to very few performance measures such as responsiveness to urgent deliveries and customer query time. Furthermore, another limitation of the research is the use of enhanced version of fuzzy AHP methods rather than using standard fuzzy AHP method in the proposed hybrid methodology. Thus, to demonstrate the robustness of the proposed approach, future research should focus on using enhanced version of fuzzy based prioritization methods for deriving group priorities/weights. For future development, warehouse managers need to consider performance measures with a focus on practices that could improve socio-technical aspects such as those related to quality of work life and sustainability. For academia, this study has shown that there are gaps in the current understanding of the factors that underpin the choice of performance measures and practices in warehouse management and in particular, the influence of supply chain managers in the choices made. 
Future studies could consider the impact of practices including organizational or national culture to understand performance in warehouses as well as investigate the primary factors that drive the understanding and selection of performance measures. In addition, it will be worthwhile to investigate the use of different technologies in warehouses and how such technologies lead to evolution and change in practices and performance measurement decisions.

\section{References:}

Aghezzaf, E. H. (2007), "Production planning and warehouse management in supply networks with inter-facility mold transfers", European Journal of Operational Research, Vol.182, No. 3, pp. 1122-1139.

Akyuz, G. A. and Erkan, T. E. (2010), "Supply chain performance measurement: a literature review”, International Journal of Production Research, Vol.48, No. 17, pp. 5137-5155.

Autry, C. W., Griffis, S. E., Goldsby, T. J. and Bobbitt, L. M. (2005), "Warehouse management systems: Resource committment, capabilities, and organisational performance", Journal of Business Logistics, Vol.26, No. 2, pp. 165-183.

Ayağ, Z. (2005), "A fuzzy AHP-based simulation approach to concept evaluation in a NPD environment", IIE Transactions, Vol. 37, No. 9, pp. 827-842.

Baker, P., and Halim, Z., (2007) "An exploration of warehouse automation implementations: cost, service and flexibility issues", Supply Chain Management: An International Journal, Vol. 12, No. 2, pp.129-138,

Banomyong, R. and Supatn, N., (2011),"Developing a supply chain performance tool for SMEs in Thailand," Supply Chain Management: An International Journal, Vol. 16, No. 1, pp. $20-31$.

Beamon, B. M. (1996), "Performance measures in supply chain management: Proceedings of the 1996 Conference on Agile and Intelligent Manufacturing Systems”, Rensselaer Polytechnic Institute, Troy, New York, NY, October 2-3.

Beamon, B. M., (1999), "Measuring supply chain performance.” International Journal of Operations and Production Management, Vol.19, No. 3, pp. 275-292.

Bennett, D., and Klug, F., (2012) "Logistics supplier integration in the automotive industry", International Journal of Operations \& Production Management, Vol.32, No.11, pp.1281-1305, 
Birou, L., Germain, R.N., Christensen, W.J., (2011) "Applied logistics knowledge impact on financial performance", International Journal of Operations \& Production Management, Vol.31, No. 8, pp.816-834,

Bowersox, D. J., Closs, D. J., Cooper, M. B. and Bowersox, J. C. (2013), Supply chain logistics management, McGraw Hill, New York.

Brito, I. S., Vieira, F., Moreira, A. and Ribeiro, R. A. (2007), "Handling conflicts in aspectual requirements compositions." In: Araujo, J. and Baniassad, E. (Eds.), Transactions on Aspect-Oriented Software Development, Vol.3, pp. 144-166.

Bromiley, P. and Rau, D. (2014), “Towards a practice based view of strategy", Strategic Management Journal, Vol.35, No. 8, pp. 1249-1256.

Cagliano, R., Caniato, F. and Spina, G. (2006), “The linkage between supply chain integration and manufacturing improvement programmes", International Journal of Operations \& Production Management, Vol.26, No. 3, pp. 282-299.

Cao, W., and Jiang, P. (2013), "Modelling on service capability maturity and resource configuration for public warehouse product service systems", International Journal of Production Research, Vol.51, No. 6, pp. 1898-1921.

Chae, B.,(2009),"Developing key performance indicators for supply chain: an industry perspective", Supply Chain Management: An International Journal, Vol.14, No.6, pp.422-428.

Chan, L. K., and Wu, M. L. (1998), "Prioritizing the technical measures in Quality Function Deployment", Quality Engineering, Vol.10, No. 3, pp. 467-479.

Chang, D. Y. (1996), “Application of the extent analysis method on fuzzy AHP”, European Journal of Operational Research, Vol.95, No. 3, pp. 649-655.

Chen, Y., Fung, R. Y. K. and Tang, J. (2006), "Rating technical attributes in fuzzy QFD by integrating fuzzy weighted average method and fuzzy expected value operator", European Journal of Operational Research, Vol.174, No. 3, pp. 1553-1566.

Chen, R., Liu, L. and Wu, J. N. (2007), "Logistics capability and its grey assessment model." Proceedings of 2007 IEEE international conference on Grey systems and intelligent services, Nanjing, China.

Chia, A., Goh, M. and Hum, S. H. (2009), "Performance measurement in supply chain entities: Balanced Scorecard Perspective”, Benchmarking: An International Journal, Vol.16, No. 5, pp. 605-620. 
Chou, W. C. and Cheng, Y. P. (2012), “A hybrid fuzzy MCDM approach for evaluating website quality of professional accounting firms", Expert Systems with Applications, Vol.39, No. 3, pp. 2783-2793.

Cohen, J. (1960), "A coefficient of agreement for nominal scales", Educational and Psychological Measurement, Vol.20, No. 1, pp. 37-46.

Colson, G., and Dorigo, F.,(2004), “A public warehouses selection support system”, European Journal of Operational Research, Vol.153, No. 2, pp. 332-349.

Cuthbertson, R. and Piotrowicz, W. (2011), "Performance measurement systems in supply chains: A framework for contextual analysis", International Journal of Productivity and Performance Management, Vol. 60, No. 6, pp.583-602.

de Koster, M. B. M., and Warffemius, P. M. J. (2005), “American, Asian and third-party international warehouse operations in Europe - A performance comparison", International Journal of Operations \& Production Management, Vol.25, No. 8, pp. 762780.

de Koster, R., Le-Duc, T. and Roodbergen, K. J. (2007), "Design and control of warehouse order picking: A literature review", European Journal of Operational Research, Vol.182, No. 2, pp. 481-501.

de Koster, M. B. M. and Balk, B. M. (2008), "Benchmarking and monitoring international warehouse operations in Europe", Production and Operations Management, Vol.17, No. 2, pp. 175-183.

de Koster, M.B.M. de, and Warffemius, P.M.J., (2005) "American, Asian and third - party international warehouse operations in Europe: A performance comparison", International Journal of Operations \& Production Management, Vol. 25, No. 8, pp.762780

Dong, Y. (2013), "Research on Employment Direction of China's Certified Public Accountant Based on Network Analytic Hierarchy Process", In Proceedings of the International Conference on Management Science and Industrial Engineering: 124-128.

Dotoli, M., Fanti, M. P. and Mangini, A. M. (2007), "Fuzzy multi-objective optimization for network design of integrated e-supply chains." International Journal of Computer Integrated Manufacturing, Vol.20, No. 6, pp. 588-601.

Erenguc, S. S., Simpson, N. C. and Vakharia, A. J. (1999), "Integrated production/distribution planning in supply chains: An invited review", European Journal of Operational Research, Vol.115, No. 2, pp. 219-236. 
Evangelista, P., Mogre, R., Perego, A., Raspagliesi, A., Sweeney, E., (2012) "A survey based analysis of IT adoption and 3PLs' performance", Supply Chain Management: An International Journal, Vol.17, No.2, pp.172-186.

Faber, N., de Koster, M. B. M. and Smidts, A. (2013), “Organizing Warehouse Management.” International Journal of Operations and Production Management, Vol.33, No. 9, pp. $1230-1256$

Faber, N., de Koster, M. B. M. and van de Velde, S. L. (2002), "Linking warehouse complexity to warehouse planning and control structure: an exploratory study of the use of warehouse management information systems", International Journal of Physical Distribution \& Logistics Management, Vol.32, No. 5, pp. 381-395.

Ganesan, S., George, M., Jap, S., Palmatier, R. W. and Weitz, B. (2009), "Supply chain management and retailer performance: Emerging trends, issues and implications for research and practice", Journal of Retailing, Vol.85, No. 1, pp. 84-94.

Gotzamanis, K., Longinidis, P.,Vouzas, F., 2010,The logistics services outsourcing dilemma: quality management and financial performance perspectives, Supply Chain Management: An International Journal, Vol.15, No. 6, pp. 438 - 453.

Green Jr, K.W., Whitten, D., Inman, R.A., (2008) "The impact of logistics performance on organizational performance in a supply chain context", Supply Chain Management: An International Journal, Vol.13, No.4, pp.317-327.

Gu, J., Goetschalckx, M., and McGinnis, L.F. (2007),'Research on warehouse operation: A comprehensive review," European Journal of Operational Research, Vol. 177, No.1, pp. $1-21$.

Gu, J., Goetschalckx, M. and McGinnis, L. F. (2010), "Research on warehouse design and performance evaluation: A comprehensive review." European Journal of Operational Research, Vol.203, No. 3, pp. 539-549.

Gunasekaran, A., Patel, C., and Tirtiroglu, E., (2001), "Performance measures and metrics in a supply chain environment", International Journal of Operations \& Production Management, Vol. 21, No. 1/2, pp. 71-87.

Hoek, R.I. van, (2001) "The contribution of performance measurement to the expansion of third party logistics alliances in the supply chain", International Journal of Operations \& Production Management, Vol.21, No.1/2, pp.15-29.

Hou, J. L., Wu, Y. J. and Yang, Y. J. (2010), “A model for storage arrangement and reallocation for storage management operations", International Journal of Computer Integrated Manufacturing, Vol.23, No. 4, pp. 369-390. 
Huan, S. H., Sheoran, S. K. and Wang, G. (2004), “A review and analysis of supply chain operations reference (SCOR) model", Supply chain management: An International Journal, Vol.9, No. 1, pp. 23-29.

Jarvenpaa, S. (1989), "The effect of task demands and graphical format on information process strategies", Management Science, Vol.35, No. 3, pp. 285-303.

Jeffers, P. I., (2010), "Embracing Sustainability. Information Technology and the Strategic Leveraging of Operations in Third-party Logistics." International Journal of Operations \& Production Management, Vol.30, No.3, pp.260-287.

Johnson, A. and McGinnis, L. (2011), "Performance measurement in the warehouse industry", IIE Transactions, Vol.43, No. 3, pp. 220-230.

Jothimani, D. and Sarmah, S. P. (2014), "Supply chain performance measurement for third party logistics”, Benchmarking: An International Journal, Vol.21, No. 6, pp. 944-963

Lai, K. H. (2004), "Service capability and performance of logistics service provider", Transportation Research - Part E Logistics and Transportation Review, Vol.40, No. 5, pp. 385-399.

Lau, H. and Nakandala, D. (2012), “A pragmatic stochastic decision model for supporting goods trans-shipments in a supply chain environment", Decision Support Systems, Vol.54, No. 1, pp. 133-141.

Lee S.M. and Rha, J. S. (2016), “Ambidextrous supply chain as a dynamic capability: building a resilient supply chain", Management Decision, Vol. 54, No.1, pp. 2-23.

Lu, C. S. and Yang, C. C. T. (2010), "Logistics service capabilities and firm performance of international distribution center operators", The Service Industries Journal, Vol.30, No. 2, pp. 281-298.

Meepetchdee, Y., and Shah, N., (2007) "Logistical network design with robustness and complexity considerations", International Journal of Physical Distribution \& Logistics Management, Vol. 37, No. 3, pp.201-222,

Milgate, M., (2001),"Supply chain complexity and delivery performance: an international exploratory study," Supply Chain Management: An International Journal, Vol. 6, No., 3, pp. $106-118$.

Min, H. (2006), "The applications of warehouse management systems: an exploratory study", International Journal of Logistics: Research and Applications, Vol.9, No. 2, pp. 111126. 
Nahm, A. Y., Solis-Galvan, L. E. Rao, S. S. and Ragu-Nathan, T. S. (2002), "The Q-sort method: assessing reliability and construct validity of questionnaire items at a pre-testing stage”, Journal of Modern Applied Statistical Methods, Vol.1, No. 1, pp. 114-125.

Nair, A. (2005), "Linking manufacturing postponement, centralised distribution and value chain flexibility with performance", International Journal of Production Research, Vol.43, No. 3, pp. 447-463.

O'Brien, C. (2013), "Fifty years of shifting paradigms", International Journal of Production Research, Vol.51, No. 23-24, pp. 6740-6745.

Pagh, J. D. and Cooper, M. C. (1998), "Supply chain postponement and speculation strategies: how to choose the right strategy", Journal of Business Logistics, Vol.19, No. 2, pp. 1333.

Park, Y. B. and Hong, S. C. (2009), "Integrated production and distribution planning for singleperiod inventory products", International Journal of Computer Integrated Manufacturing, Vol.22, No. 5, pp. 443-457.

Petersen, C.G., (2002) "Considerations in order picking zone configuration", International Journal of Operations \& Production Management, Vol.22, No. 7, pp.793-805,

Petersen, C.G., Siu, C., Heiser, D.R., (2005) "Improving order picking performance utilizing slotting and golden zone storage", International Journal of Operations \& Production Management, Vol.25, No.10, pp.997-1012.

Pettit, T.J., Fiksel, J. and Croxton, K.L. (2010, "Ensuring supply chain resilience: development of a conceptual framework", Journal of business logistics, Vol. 31, No. 1, pp.1-21.

Poon, T.C., Choy, K.L., Chow, H.K.H., Lau, H.C.W., Chan, F.T.S., Ho, K.C., (2009), “A RFID case-based logistics resource management system for managing order-picking operations in warehouses", Expert systems with applications, Vol.36, No.4, pp. 82778301

Rahman, S., and Wu, Y-C. J., (2011) "Logistics outsourcing in China: the manufacturer cum - supplier perspective", Supply Chain Management: An International Journal, Vol.16, No. 6, pp. 462-473

Rajesh, R., Pugazhendhi, S. and Ganesh, K. (2011), "Towards taxonomy architecture of knowledge management for third-party logistics service provider", Benchmarking: An International Journal, Vol.18, No. 1, pp. 42-68. 
Reisinger, H., Cravens, K. and Tell, N. (2003), "Prioritizing performance measures within the Balanced Scorecard framework", Management International Review, Vol.43, No. 4, pp. 429-437.

Roberts, H., and Philip, I. (1996), "Prioritizing performance measures for geriatric medical services: what do the purchasers and providers think?", Age and Aging, Vol.25, No. 4, pp. 326-328

Roy, D., Krishnamurthy, A. Heragu. S. S. and Malmborg, C. J. (2012), "Performance analysis and design trade-offs in warehouses with autonomous vehicle technology", IIE Transactions, Vol.44, No. 12, pp. 1045-1060.

Saaty, T. L. (1990), "How to make a decision: The Analytic Hierarchy Process", European Journal of Operational Research, Vol.48, No. 1, pp. 9-26.

Saaty, T. L. (1994), Fundamentals of decision making and priority theory with the analytic hierarchy process, RWS Publications, Pittsburgh.

Samaranayake, P., Laosirihongthong, T. Chan, F. T. S. (2011), "Integration of manufacturing and distribution networks in a global car company - network models and numerical simulation", International Journal of Production Research, Vol.49, No. 11, pp. 3127 3149.

Santarelli, G., Abidi, H., Klumpp, M., \& Regattieri, A. (2015), "Humanitarian supply chains and performance measurement schemes in practice", International Journal of Productivity and Performance Management, Vol. 64, No. 6, pp. 784-810.

Sharma, D., Scholar, R. and Sahay, B. S. ( 2004), "Modeling distributor performance index using the system dynamics approach", Asia Pacific Journal of Marketing and Logistics, Vol.16, No. 3, pp. 37-67.

Sharma, S. and Shah, B. (2015), “A proposed hybrid storage assignment framework: a case study", International Journal of Productivity and Performance Management, Vol. 64, No. 6, pp. 870-892.

Sharma, S. and Shah, B. (2016), "Towards lean warehouse: transformation and assessment using RTD and ANP", International Journal of Productivity and Performance Management, Vol. 65, No. 4, pp. 571-599.

Shepherd, C. and Günter, H. (2006), "Measuring supply chain performance: current research and future directions", International Journal of Productivity and Performance Management, Vol. 55, No. 3/4, pp. 242-258. 
Sheu, C., Yen, S.J.R, Chae, B., (2006),"Determinants of supplier-retailer collaboration: evidence from an international study," International Journal of Operations \& Production Management, Vol. 26, No. 1, pp. 24 - 49.

Smith, N. W. and Smith, L. L. (1996), "Field theory in science: its role as a necessary and sufficient condition in psychology”, Psychological Record, Vol.46, No. 1, pp. 3-20.

Sohn, S.Y., Han, H.K., Jeon, H.J., (2007), "Development of an Air Force Warehouse Logistics Index to continuously improve logistics capabilities", European Journal of Operational Research, Vol.183, No. 1, pp. 148-161.

Staudt, F. H., Alpan, G., Di Mascolo, M. and Rodriguez, C. M. T. (2015), "Warehouse performance measurement: a literature review", International Journal of Production Research, Vol.53, No. 18, pp. 5524-5544.

Tse, Y. K., Tan, K. H., Ting, S. L., Choy, K. L., Ho, G. T. S. and Chung, S. H. (2012), "Improving postponement operation in warehouse: an intelligent pick-and-pack decision support system", International Journal of Production Research, Vol.50, No. 24, pp. 7181-7197.

Vaziri J. and Beheshtinia, M. A. (2016), “A holistic fuzzy approach to create competitive advantage via quality management in services industry (case study: life-insurance services)", Management Decision, Vol. 54, No. 8, pp. 2035 - 2062

Visich, J.K., Li, S., Khumawala, B.M., Reyes, P.M., (2009) "Empirical evidence of RFID impacts on supply chain performance", International Journal of Operations \& Production Management, Vol.29, No.12, pp.1290-1315.

Wang, Y. M., Luo, Y. and Hua, Z. S. (2008), "On the extent analysis method for fuzzy AHP and its applications", European Journal of Operational Research, Vol.186, No. 2, pp. 735-747.

Wang, J. Z., Hsieh, S. T. and Hsu, P. Y. (2012), “Advanced sales and operations planning framework in a company supply chain", International Journal of Computer Integrated Manufacturing, Vol.25, No. 3, pp. 248-262.

Wong, C.Y. and Karia, N. ( 2010), "Explaining the competitive advantage of logistics service providers: A resource-based view approach", International Journal of Production Economics, Vol.128, No. 1, pp. 51-67.

Wouters, M., and Sportel, M., (2005) "The role of existing measures in developing and implementing performance measurement systems", International Journal of Operations \& Production Management, Vol. 25, No.11, pp.1 062-1082. 
Xia, Y. and Tang, T. L. P. (2011), ”Sustainability in supply chain management: suggestions for the auto industry", Management Decision, Vol. 49, No. 4, pp. 495-512.

Yang, W. Chan, F.T.S., and Kumar, V., (2012), “Optimizing replenishment polices using Genetic Algorithm for single warehouse multi-retailer system“, Expert Systems with Applications, Vol. 39, No.3, pp. 3081-3086.

Yu, K., Cadeaux, J., Song, H., (2012) "Alternative forms of fit in distribution flexibility strategies", International Journal of Operations \& Production Management, Vol.32, No. 10, pp.1199-1227,

Zailani, S. and Rajagopal, P. (2005), "Supply chain integration and performance: US versus East Asian companies", Supply Chain Management: An International Journal, Vol.10, No. 5, pp. 379-393. 